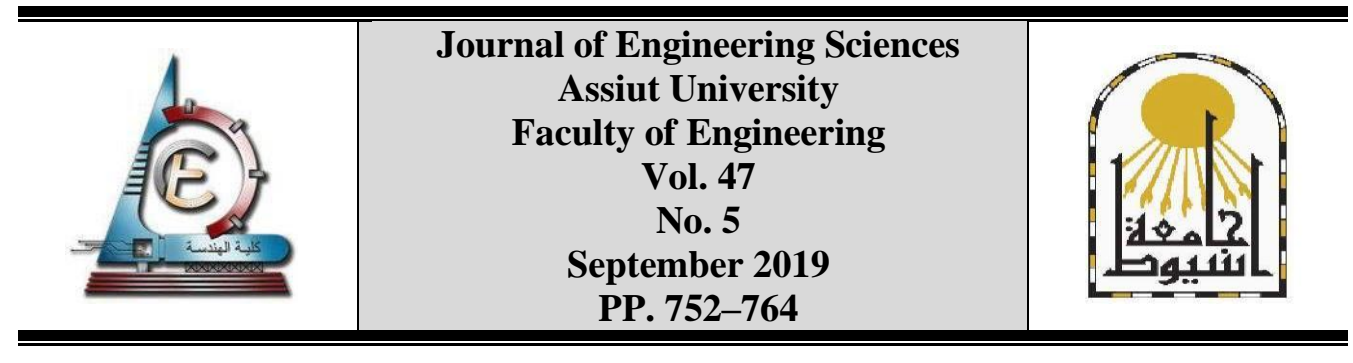

\title{
THE FUTUER OF URBAN GROWTH IN EGYPT ASSESSMENT OF CURRENT TRENDS AND FORGING NEW APPROACHES FOR SUSTAINABLE DEVELOPMENT
}

\author{
Ahmed Mohammed Emam Hammad \\ October High Institute for Engineering and Technology
}

Received 4 April 2019; Accepted 1 September 2019

\begin{abstract}
Since the seventies of the last century, Egypt has taken serious steps towards adopting the policy of establishing new cities to alleviate the encroachments on agricultural lands and to re-distribute the population on the desert lands adjacent to the valley, and then the homogeneous re-distribution of the population over the entire area of the country to achieve economic, social and security objectives. This policy has gone through four phases or generations of new cities of various types (independent, satellite and twin cities), but for economic, social and implementation reasons, this policy has not been able to achieve its full objectives. As a result the greater Cairo became a huge urban agglomerate with internal trips of more than $100 \mathrm{~km}$ length, making its service facilities and networks is too difficult, and worsened its environment, and pollution rates have increased to unprecedented rates, However, the urban area of the country has not increased by more than $3 \%$ in five decades and its population and urban densities- in the Nile valley and its surroundings- has doubled, while most of the European countries are establishing small and medium urban communities with a population of between 10000 and 50,000 and between 50000 and 500000, which can be free from mechanical movement, which preserves the environment and reduces pollution rates, as the problems and challenges faced by mega cities than the small and medium communities, Thus, the research concludes that the future of the Egyptian urban sprawl should adopt the policy of distribution of small and medium urban settlements on the axes of regional roads and consider them as axes of development to redistribute the homogeneous population over the entire country rather than the too long agglomeration and the mega cities.
\end{abstract}

Keywords: Urban growth, sustainable development, small settlement.

\section{Introduction}

The world is suffering from critical population growth - especially in the last two decades - with the world population estimated at 7.9 billion at the beginning of 2019 , according to UN estimates. The world's population is expected to reach 9.5 billion by 2050 .

At the same time, the United Nations estimates the total area of the urban land, (including all buildings, roads and others), at about 1 million $\mathrm{km} 2$, equivalent to approximately the size of Egypt. This area is about three times as high as it is now by 2050, the urbanization rate is increasing rapidly with an average of $58 \%$ of the world's population about $44 \%$ in Egypt (according to United Nations and World Bank estimation). [1] 
In comparison, according to the existing definitions of urban place in Egypt, the United Nations Population Division of the Department of Economic and Social Affairs, 2003, estimates an increase of urban population of Egypt to reach about 52 million inhabitants by 2025, while rural population will reach about 49 million inhabitants. A disaster facing humanity and warning of a huge food gap will inevitably affect the global food balance. This is a part of the expense of arable land in the world as a whole. [2]

Therefore, all countries is obliged to review their plans to cope with this potential disaster, and Egypt has felt this problem that threatens the agricultural lands in the delta and valley, since the last third of the last century began to approach a policy of expansion on the desert lands by creating a series of new cities and twin cities \& satellites on the desert for facing this urbanization growth.

This research discusses the Egyptian urban policies conducted whenever the state started to create new urban communities, and the impact of these policies on achieving urban goals set for these cities.

Therefor the Egyptian government is at a crossroads for the future of Egyptian urban growth between two policies (small \& medium settlements, or the expansion of the existing cities into metropolises with millions of inhabitants through the enlargement of the cities areas \& population).

It is rare to find a report on Egypt's spatial development that does not include a phrase along the lines of: "95\% of the population lives on 4\% of the land area," which often leads to images of relentless overcrowding in the Nile Valley and the Delta, and which typically serves as the entry point to discussions of the imperative that Egypt should expand into the desert. [3]

However, when implemented, these policies were in conflict with economic, social, and demographic policies that made these plans far more deviant than planned.

These new urban communities - especially those around Greater Cairo - have sprawl formally and informally until they produce an agglomeration beyond the $120 \mathrm{~km}$ length.

More than 1/3 of the population of the Arab Republic of Egypt is concentrated in the central area (Greater Cairo), which resulted a greater urban crisis than it faced at the beginning of the planning of the new urban communities while the Western desert and its governorates (New Valley and Marsa Matrouh and the other oases) are suffering from lack in Population growth and inhabitants and urban density, despite the availability of the natural resources of development.

Another crisis has emerged from Cairo's massive sprawl and its transformation into a mega-city that is difficult to be controlled, served and provided with adequate infrastructure for its density and sprawl.

Therefor a core questions is asked: Should it be better to continue sprawl the urbanization around Greater Cairo, or to be oriented towards Western and Eastern desert lands and to exploit their resources?

Is it better in this case to rely on the creation of large cities in the desert or the reliance on small urban settlements along the regional road hubs? especially as the world enters the age of dependence on renewable energy that can be produced for each community separately (not central) to the adoption of these communities on their selves with the possibility of linking them later to the General Energy Network. 
Therefore, it is necessary to correct the course of the policy of urbanization in Egypt by using methods that achieve the objectives for which the government started to establish the new cities. That will be achieved by controlling the urban extensions and population densities in the new and satellite cities, and establishing other communities on the regional road networks in the desert areas leading to the homogeneous spread of population, protecting the Green Valley (to bridge the food gap caused by the erosion of cultivated fertile areas), improving the environment, reducing the rates of pollution, achieving sustainable development, and strengthening the Egyptian national security by not leaving the country margins for criminal activities and terrorism.

\section{Research methodology}

This research adopted the deductive methodology through analyzing of the Egyptian urban policies for the past five decades; since the starting of recognition of the new urban communities, and the results considering the forged aims and how much these policies actually achieved of those aims using quantitative data. And comparing with the European urban pattern, which considers the policies of establishing small and medium urban settlements. Then it can be expected what are the concepts of achieving sustainable development based on discovering and exploiting the natural resources of the entire area of Egypt will be.

Start with a theoretical approach to show the concept and definitions of small \& medium urban settlements as a base of sustainable development in European urban fabric, in addition to the rural, and urban settlements in Delta and Upper Egypt, which are considered as natural spontaneous Egyptian fabric.

The analytical approach, in which the research studies the appropriate settlements' size according to historical, Environmental, physiological, and walk-ability considerations, and analyses the results of the Egyptian urban polices in comparison with its goals determined at the strategic design phase, thin attempts to determine reasons of deviation.

The last part of the study discusses polices of the future of the Egyptian urban fabric, which are expected to achieve a sustainable development.

\section{Literature review about appropriate size of communities}

Griffith Taylor in his book, Towns and Cities Urban Geography, points out that the optimal size of a city is determined when it is difficult to obtain sufficient water for the needs of the population. [4]

T. Duncan [5] believes that the population of the city is 50 thousand to 100 thousand, which is a choice to be 30 thousand people.

The concept of garden city which was created 1898 by Sir Ebenzer Howard determined that the garden city is a compact town of about 6000 acres; it accommodates a maximum population of 32,000 persons with parks and private lawn everywhere. [6]

Sir Howard explained his concept of growth that whenever the main city reaches its target population, new interconnected nodes can be developed. When a Garden City is built up and its population has reached 32,000 persons. How will it grow? It will grow by establishing another city some little distance beyond its own zone of 'country', so that the new town may have a zone of country of its own. 
Letchworth was the first garden city developed in 1903 by Barry Parker \& Raymond Unwin after having won the competition to build first garden city. It is 34 miles away from London with an area of 5000 acres and population of 30000 persons with living area of 1250 acres and 2500 acres of rural green belt. It was small enough which required no vehicular transportation. [7]

The most important criteria that must be taken into account when determining the sizes of cities and villages and urban settlements in general:

Economical standards; Where economic resources available for those cities are estimated, whether surrounding it or by assessing the availability of the origin cities and the province of the city.

\section{Determining the appropriate size of the urban communities and distances between them}

Some believe the sizes of cities and residential communities are measured by the level of facilities (cost and quality) provided by the cities to their inhabitants, others relate them to the standard of living of their population, some whom relate the size of the city by the ease of movement between its different parts, and who relate its size to economic resources and natural resources. (Cities bordered by natural resources, huge and diverse, attracting a large number of the population and occupy a larger area than others), because of the investments and greater number of job opportunities provided by it, and all these considerations must be taken into account when choosing the optimal size of the city.

The appropriate size of settlements according to the vision of this research is determined by the walking ability of people. (The likely human speed of walking is $5 \mathrm{~km} / \mathrm{h}$ for about 9 hours walking per week, an average person's walking speed per hour is (6 kilometers), [ 8]

\section{Small \& medium urban settlements (definitions \& concepts)}

Small and medium sized urban areas (SMUAs) defined as urban areas with 5,000 to 50,000 inhabitants. (This definition is based on a combination of the OECD-EC Degree of urbanization classification and the European wide research project "TOWN - Small and medium sized towns in their functional territorial context "carried out within the ESPON Program)[9]

SMUAs have been at the core of urbanization in Europe. Europe is an urban continent but unlike other continents the urban pattern of Europe is more polycentric with relatively small cities. About $70 \%$ of Europe's population is living in urban areas, but about $66 \%$ of Europe's urban dwellers are residing in urban areas with less than 500,000 inhabitants. This is considerably more than in other world regions, especially Northern America, where only one third of the population lives in smaller cities.

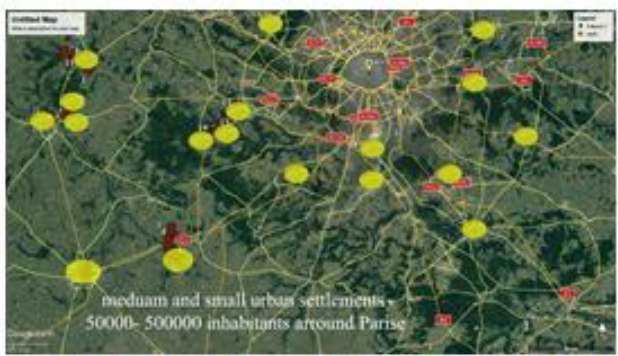

Fig. 1. Small\& medium size settlement around Paris such as Bethemont-la foret with 4800 inhabitants [16]

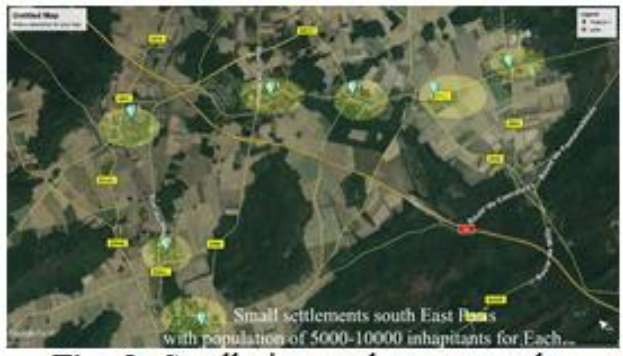

Fig. 2. Small size settlement south east Paris such as Villers Adams with 5600 inhabitants [16] 
JES, Assiut University, Faculty of Engineering, Vol. 47, No. 5, September 2019, pp. 752-764

According to the TOWN research $24.2 \%$ of the European population lives in 8,350 SMUAs that are unevenly distributed across Europe, with a concentration of SMUAs in the area stretching from northern England towards the southern Rhine valley and northern Italy. [10]

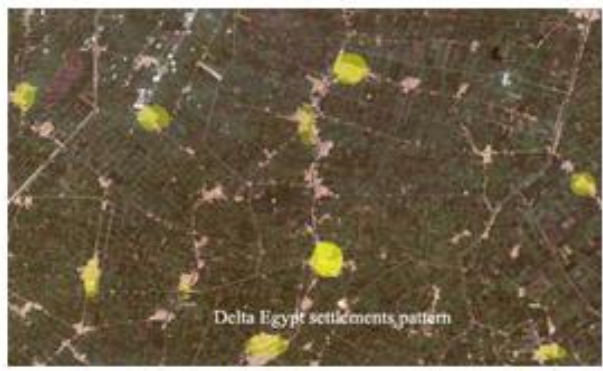

Fig. 3. Small rural settlements pattern (Delta Egypt) such as Izbet-El-Kom , Gharbia, with 7600 inhapitants. (CAMPAS) (Population 2016)

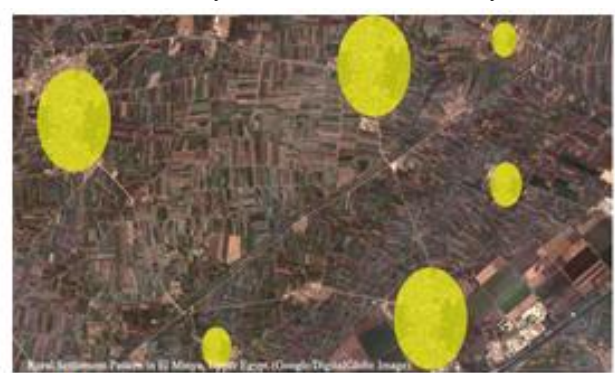

Fig. 4. Small rural Settlements pattern (upper Egypt) such as Nagaa AL-qubibah Qena with 12204 inhabitants. (CAMPAS). (Population 2016)

\section{Challenges and Opportunities for Small and medium urban settlements}

The megacities are only on the rise. More than half of the world's population now lives in cities, and the number of megacities with populations of more than 10 million has risen from three megacities in 1975 to around 20megacities now and still growing. As a result, the megacities of today have become the hotspots for emissions that have serious implications in air pollution and climate change. Moreover, these population hubs have caused severe strain on vital natural resources such as water and soil quality. These impacts are felt not just locally but regionally as well as globally. For this reason, the environmental impact of megacities is a phenomenon that needs to be addressed by policy-makers. [11]

From the information mentioned above the it can be included that the appropriate model for the Egyptian future sprawl is the Small urban settlements with a population between 10,000 and 50,000 and a population density of about 30persons per feddan, create an urban settlement of area that does not exceed $7 \mathrm{~km} 2$ and with dimensions not exceeding $2.5 \mathrm{~km} * 3 \mathrm{~km}$. This means that this residential complex can dispense vehicles for pedestrian movement and act as a car-free area with pedestrian network.

This helps to reduce the pollution resulting from traffic across the cities, reduce the consumption of energy, and restore the intimate relationship between the city and its residents significantly. "The Government needs to expedite a wider variety of policies which can cover and regulate the impact of the megacities on climate change as well.. These emissions of greenhouse gases and pollutants impact both, the composition of the atmosphere and the climate. This in turn is expediting climate change and its adverse impacts". Kota Sriraj," The megacity problem, the pioneer magazine13th. Sept. 2018

Small and medium urban settlements can be constructed even if the available space is relatively small by virtue of the topography surrounding the site.

Small and medium-sized urban settlements can be based on a relatively low-cost economic opportunity or relatively low-production natural resource, where the required job opportunities are lower and can depend on the employment opportunities offered by small and micro industries and traditional crafts. 
Jobs of these communities can vary, and each of them is characterized by a particular activity on which it is based on. It is considered the main economic activity of the population, according to what is available on the site of comparative advantages and opportunities.

Small and medium-sized urban settlements do not need large and complex infrastructure networks and huge \& expensive service stations (electricity, sewage, water supply, telephones ... etc.).

Social life in Small and medium-sized urban settlements is more interrelated, and the relationship between their populations is more intimate and creates safer communities, and less in crime rates, since acquaintance between the population reduces criminal behavior.

In Small and medium-sized urban settlements, urban and population densities can be more controlled and future extensions can be adjusted according to plans.

Small and medium-sized urban settlements are easy to manage because their problems are less and can easily provide administrative cadres for local administration easily.

The challenges facing these communities are:

- Their contribution to the national capital is relatively lower.

- The multiplicity of local administrations is sometimes an economic burden because each group needs separate management.

- The lack of economic capacity of the state to develop the entire axis and the extension of infrastructure networks along the axis of development.

- The paucity of what can be collected from the contributions of the population to selfgenerated activities\& NPOs compared to urban communities with a population of more than 500,000, as large communities can collect much larger contributions to common public services that are self-generated.

\section{Efforts of the government for adopting policies of creating new cities}

There were logical reasons for the government's thought of the policy of planning and implementing the new cities and satellite. These motives were similar to the circumstances of the countries that adopted this policy, led by England and France, where the two countries - specifically and Europe in general - passed by the same conditions after the two world wars. However the Egyptian situation was more in need to adopt the same policy for the following reasons:-

-The density of the population in the capital and the central cities in the governorates increased from 276 persons / $\mathrm{km} 2$ at the beginning of the twentieth century to more than 1685 persons / $\mathrm{km} 2$ in 1996, and now it is about 4825 persons/Km2 in Qalubia (Statistics: (CAMPAS) (Population 2016) which increased the pressure on the urban infrastructure networks of the old cities, and the resulting urban deterioration as the increase in road traffic congestion[13] \& the erosion of agricultural lands[14], increased consumption of energy, water and sanitation, with huge differences (gap) in the levels of incomes, and the increasing of pollution rates [15], it also causes a lack of urban facilities and open spaces and recreational areas in the capital and its suburbs, where green \&cultivated areas and recreational facilities were reduced to less than $0.2 \mathrm{~m} 2$ per person in Cairo.[12]

\section{Egyptian Urban Policy since mid-seventies (new urban communities' establishment) -"problem complexity"}

Egypt began the policy of planning new cities since the mid-seventies of the last century by implementing a group of different new cities (independent cities, satellites, edge cities, 
and twin cities) according to a specific urban strategy to achieve the specific objectives mentioned above. The most important objective was the reduction of congestion in the main cities and reducing the pressure on them \& the consequent urban deterioration caused, the spread of slums, redistribution of the population on the whole area of the country, protection of the fertile Nile Valley from erosion due to urban encroachment (which represents the strategic inventory of Egyptian food security) with the redistribution of the population closer to homogeneity on the whole Area of the country.

The last episode of this policy to reduce the pressure on the capital was specifically the implementation of ten residential communities around greater Cairo and linking them by the ring road and leaving the spaces between the origin city and those communities as a green strip used as open areas and recreational services.

After applying that, the urban estate of these communities expanded, doubled the urban agglomeration remarkably, and extended to the interfaces (green strips). This led to uncontrolled urban growth with boundaries extending to over 100 kilometers.

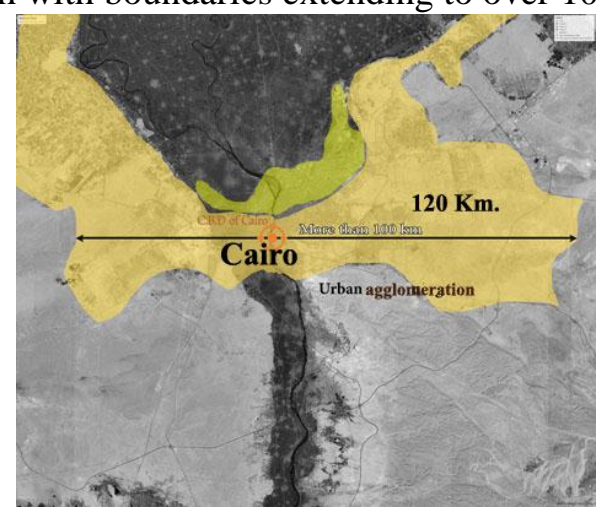

Fig. 5. Too long agglomeration

\section{Reasons for failure to achieve goals of urban policy - implementation problems}

In fact, Egypt's urbanization policy has not only failed to achieve its basic objectives, but has also put more pressure on its main cities (especially Cairo which has maintained relatively high urban density), to more than "4600 persons per square kilometer" in Qalioubia, which is one of the governorates of the Greater Cairo Region. The policies did not achieve homogeneous distribution of population on the entire area of the country. And the population density in the "New valley" governorate remained less than 2 persons per square kilometer - although the new valley has huge natural resources and clean un-contaminated environment. 
Table1.

Egyptian governorates population \& densities, Source: Central Agency for Public Mobilization and Statistics (CAMPAS) (Population 2016)[14]

\begin{tabular}{|c|c|c|}
\hline Density person $\mathrm{km} 2$ & Population & Govemorate \\
\hline $3,060.1$ & $9,440,374$ & Cairo \\
\hline 588.8 & $7,762,792$ & Giza \\
\hline $1,352.2$ & $6,640,664$ & Sharkia \\
\hline $1,716.9$ & $6,074,446$ & Daqhlya \\
\hline 606.5 & $5,959,050$ & Behira \\
\hline 164.5 & $5,309,254$ & Menya \\
\hline $4,640.1$ & $5,215,446$ & Qalyobia \\
\hline $2,131.3$ & $4,901,910$ & Alexandria \\
\hline 2,499 & $4,852,968$ & Al-gharbia \\
\hline 422.1 & $4,734,676$ & Sohag \\
\hline 318.1 & $4,364,111$ & Assiut \\
\hline $1,614.7$ & $4,035,137$ & Monofya \\
\hline 540.6 & $3,280,103$ & Fayoum \\
\hline 937.2 & $3,249,268$ & Kafr El-Sheikh \\
\hline 348.4 & $3,128,194$ & Qena \\
\hline 268.7 & $2,943,740$ & Beny-sweif \\
\hline 23.4 & $1,466,965$ & Aswan \\
\hline $1,494.1$ & $1,359,643$ & Damietta \\
\hline 238.7 & $1,209,663$ & Ismailia \\
\hline 396.5 & $1,173,753$ & Luxor \\
\hline 504.5 & 678,564 & Port Said \\
\hline 70.7 & 636,841 & Suez \\
\hline 2.8 & 468,218 & Matrouh \\
\hline 16.2 & 445,811 & North Sinai \\
\hline 3 & 354,263 & Red Sea \\
\hline 0.5 & 230,591 & New Valley \\
\hline 5.4 & 169,822 & South Sinai \\
\hline
\end{tabular}

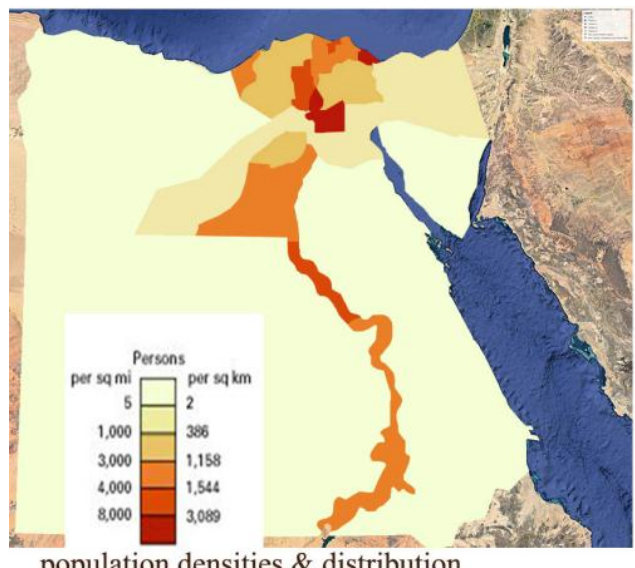

Fig. 6. population distribution over the country (CAMPAS) (Population 2016)

The governmental inability to achieve the main objectives of the urban policy is due to a number of reasons, including:

- Not following long-term strategic plans in which the plan is completed and respected during implementation and correcting it-if necessary- without circumventing the plan itself.

- By looking at the map of the Egyptian urbanization now, it is clear that most of the urban growth occurred in the vicinity of Greater Cairo, most of the independent cities 
and its satellites. And the urban developed areas between them without control therefore it was connected by developing and re-planed as housing instead of being open $\&$ recreational areas, that caused a continued urbanization that extends to more than $100 \mathrm{~km}$ distance.

-Increasing the urban spaces of some new cities and their satellites without looking at regional and national strategic plans.

- Considering the new cities and especially the satellites around Cairo as a source of national income and investing in it, and it became a quick mean for the direct and guaranteed return of the state fund.

- The government is going to implement new "millions cities" near the existing urban areas such as the New administration Capital with 6,5 million inhabitants.

-Incompatibility between economic development plans and urbanization plans; always urbanization follows economic development, and not vice versa.

- Continued neglecting and ignoring the development of marginal regions such as the "New Valley" region and the northwest region of Marsa Matrouh and Siwa.

- Lack of financial resources necessary to extend the infrastructure networks to required areas.

- The inability to control and adjust population densities increasing and placing binding restrictions for all stake holders to respect the approved plans.

\section{Correction of the Egyptian urban trends to achieve all goals}

There is no doubt there have been some successes and achieved, but the remaining unachieved objectives are currently a must to be achieved due to the economic, security and demographic challenges that Egypt faces. The most important of these goals is the achievement of homogeneous population distribution and reducing the resulted pressure from population congestion and high density.

This can be achieved by allowing the horizontal extension and exploitation of existing and planned roads and infrastructure networks, increasing their lengths and directing them towards marginal areas, considering them as axes of development, adopting the policy of small and medium urban settlement spread on the main axes of the country, and creating productive investment opportunities that lead to creating job opportunities and population attraction activities.

Adopting the policy of establishing Small and medium urban settlements helps to carry out the horizontal spread of the population more than the millions cities can do, which need more time to be built, and need to be more centralized, and are more vulnerable for occupancy.

But small settlements can spread while maintaining their population density and their expansion is limited by the presence of other communities nearby. 


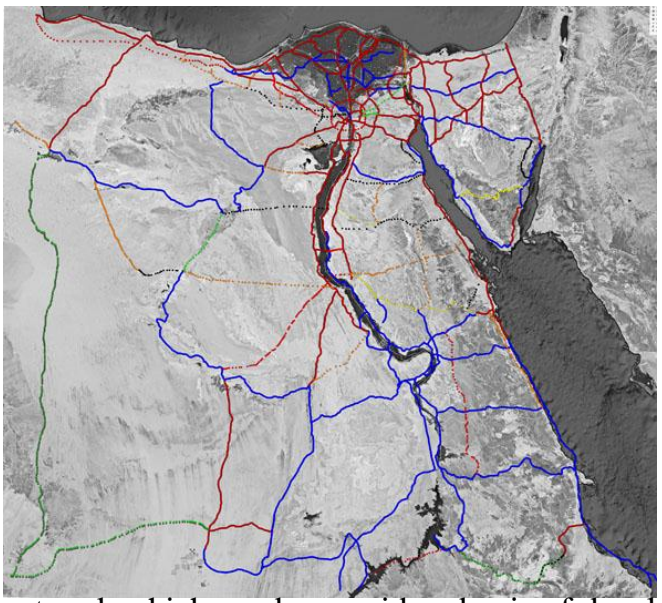

Fig. 7. Regional roads network which can be considered axis of development (General Authority for Roads, Bridges and land Transport (GARBLT)[15]

\section{Vision for Egyptian future urbanization}

It is obvious that the future of Egyptian urbanization have to adopt the horizontal orientation growth and sprawl by creating small and medium urban settlements (S\&MUSs) along the regional roads network with thousands of KMs length in order to discover and exploit the natural available resources to strong viable economic considerations, not to adopt the agglomeration around the greater Cairo and the linear axe of the Nile river and valley.

From the above studies \& analysis This research will consider that the appropriate Egyptian urban pattern is the Small \& medium size urban settlements (SMUSs) similar to European pattern with a population between 10,000 and 50,000 and with a population density of 30 persons per feddan, create an urban complex of area that not exceed $7 \mathrm{~km} 2$ and with dimensions not exceeding $(2.5 \mathrm{~km} * 3 \mathrm{~km})$.

This trend may be the Egyptian model of the concept of "The Garden City" of Sir Ebenzer Howard, which can be proper now for the future of the Egyptian urban growth.

For example; a city like Assiut (A) (400 km south Cairo) and about $200 \mathrm{~km}$ to the north from Qena (B), the concept of the plan is creating a (S\&MUSs) $5 \mathrm{~km}$ from (A) and another one $10 \mathrm{~km}$ from (A) leaving the area $(2.5 \mathrm{~km})$ between both as open spaces for economic activities (industrial, agricultural, mining, generating green electricity....etc.) These (S\&MUSs) will be 5 $\mathrm{km}$ away from the main road with a paved ring road and the internal pathways - inside the community - will be only for pedestrian and Emergency. And it will be repeated every $10 \mathrm{~km}$.

In the other side of the road it will be repeated in staggered location. Therefore, the road from both sides will be inhabited and save.

At the same time other (S\&MUSs) will be constructed $5 \mathrm{~km}$ from (B) towards (A). 


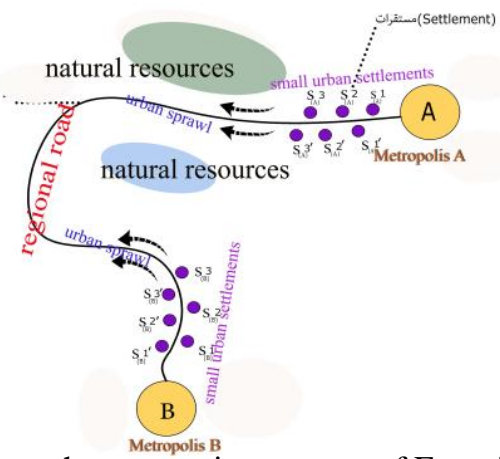

Fig. 8. Shows the appropriate pattern of Egyptian urban sprawl

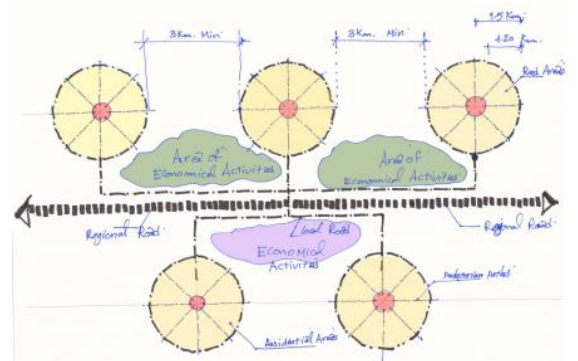

Fig. 9. Exploiting the regional axis to construct (S\&MUSs) Egyptian model for the new garden city

\section{Conclusions}

Through the above analyses of the current Egyptian urban situation and the study of the country's plans to determine the future of urban growth in Egypt to cope with the increasing in population, the following can be concluded:

Despite the efforts made in the establishment of new cities of all categories ( independent, satellite, and twins cities) they have not succeeded in achieving their objectives (protecting agricultural fertile land in the Nile Valley, achieving the homogeneous distribution of the population throughout the entire area of the country, and achieving comprehensive urban development).

Over the past five decades, the Egyptian urban area has increased by an additional 3\% despite the size of the new Egyptian cities that have been created.

The sizes of urban agglomerations around greater Cairo and the other major cities in the Nile Valley, which contributed to the erosion of fertile agricultural land, led to the spread of informal areas, and the Egyptian urbanization became largely uncontrolled.

The idea of small and medium-sized urban communities( productive and sustainable) with a population of 10,000 to 50,000 inhabitants- is successful in the European countries and North America, which use to adopt their urban growth, this concept is not new as it is matched with the concept of the "garden city" of the famous English planner Sir Ebenzer Howard, as well as related to the way of the urban distribution of the Rural urban settlements in the Egyptian Delta, The Nile Valley and Upper Egypt.

The lengths of Egypt's regional road network,( existing and future planned in Egypt), allow it to be a hub for urban development extending throughout the country. 


\section{Recommendations}

The Egyptian Ministry of Housing and its authorities which are responsible for urban development should study the possibility of trending urban sprawl to the marginal areas of western and eastern desert and north Sinai, and rely on the exploration of natural resources in those areas as resources of development, and rely on the creation of Economical activities such as: Production of renewable energy (solar energy), mining, grazing and agriculture (if water sources are available).

The research opens new trends to conduct more studies towards encouraging the involving in the desert, and the reduction of urban agglomeration around the valley and delta, by studying the locations of natural resources in the desert, and studying the possibility of establishing decentralized urban communities and infrastructure networks, and connecting Energy-producing communities with the national electricity grid.

\section{REFERENCES}

[1] United Nations, Department of Economic and Social Affairs, Population Division (2018). The World's Cities in 2018 -Data Booklet (ST/ESA/ SER.A/417).

[2]VOLUME ONE URBAN SECTOR UPDATE, Sustainable Development Department Middle East \& North Africa Region, Document of the World Bank, JUNE, 2008

[3] World bank report “ARAB REPUBLIC OF EGYPT URBAN SECTOR UPDATE” 2008

[4] Griffith Taylor, Towns and Cities Urban Geography

[5]Dustin T. Duncan is an associate professor in the Department of Population Health at the New York University School of Medicine, Neighborhoods and Health (2nd edition) with Ichiro Kawachi (Oxford University Press, 2018).

[6] Sir Ebenezer Howard, Garden Cities of To-morrow (1898)

[7] Garden City Movement a concept in Urban Planning by Sir Ebenzer Howard, Published by admin Category -Evolution of Human Settlement , 2015

[8] R. Mcneill Alexander Energetics and optimization of human walking and running, American journal of human biology 14:641(2002).

[9] Dijkstra, L. \& Poelman, H. (2012) Cities in Europe: the new OECD-EC definition

[10] 1 Challenges of Small and Medium-Sized Urban Areas (SMUAs), their economic growth potential and impact on territorial development in the European Union and Latvia, 2015

[11] Kota Sriraj,” The mega city problem, the pioneer magazine13th. Sept. 2018.

[12] https://bigsnowball.com/content/cairo-world's-most-polluted-city-'no'-says-government'probably'-say-its-suffering-residents

[13] Ahmed Emam, using rooftops of Cairo's buildings as a recreational Areas and open spaces, master thesis, Cairo university, 2000

[14]Central Agency for Public Mobilization and Statistics (CAMPAS) (Population 2016)

[15](General Authority for Roads, Bridges and land Transport (GARBLT)

[16]https://www.britannica.com/place/France/Economy 


\section{مستقبل الإمتداد العمراني بمصر}

\section{في ضوء تقييم التوجهات العمرانية الحالية وإتباع سياسات تحقق التنمية المستدامة}

الملخص العربى

بدأت مصر منذ سبعينات القرن الماضـي في إتخـاذ خطو ات جـادة في إتبـاع سياسـة إنشـاء المدن الجديدة

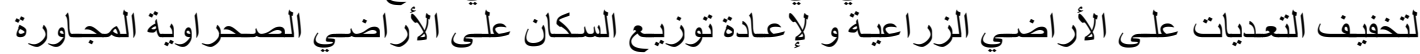



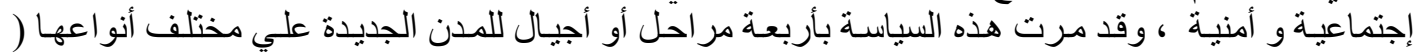

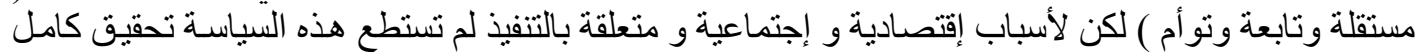

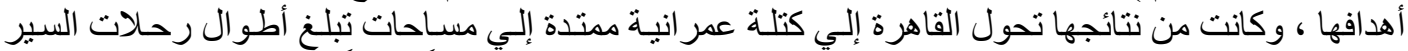

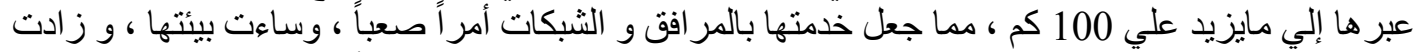

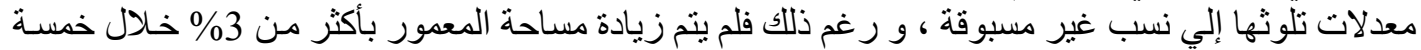

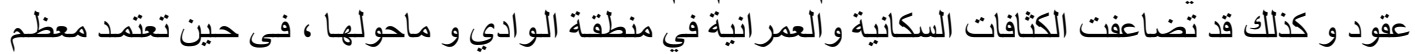

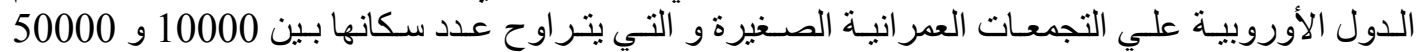

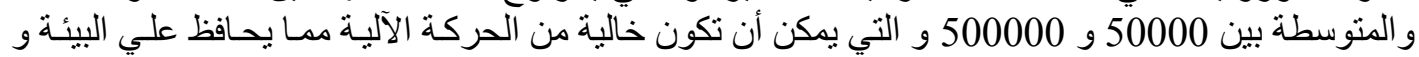

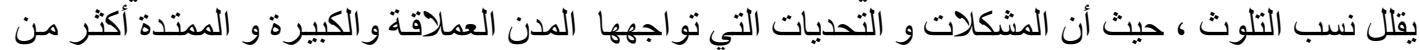

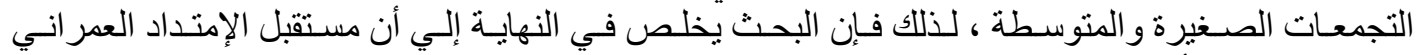

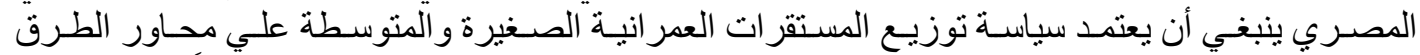

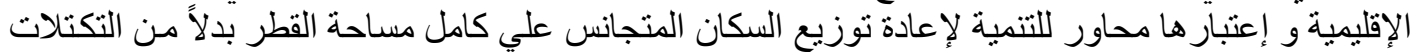

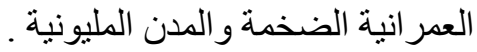

